\title{
Environmental Regulation of Methanol and Formaldehyde Metabolism by Methylophilus methylotrophus
}

\author{
By COLIN W. JONES, ${ }^{1 *}$ JACQUELINE A. GREENWOOD, \\ SHIRLEY M. BURTON, ${ }^{1}$ HELENA SANTOS ${ }^{2}$ AND DAVID L. TURNER ${ }^{2}$ \\ Departments of ${ }^{1}$ Biochemistry and ${ }^{2}$ Chemistry, University of Leicester, Leicester LEI 7RH, UK
}

(Received 9 January 1987; revised 17 February 1987)

Methylophilus methylotrophus was grown in continuous culture at different dilution rates under either methanol or oxygen limitation. Methanol dehydrogenase and formate oxidation were repressed by the presence of high concentrations of methanol in the growth medium, whereas hexulose phosphate synthase was constitutive and the glucose-6-phosphate and 6-phosphogluconate dehydrogenases were regulated only by the growth rate. Chemical analysis and ${ }^{13} \mathrm{C}$ NMR spectroscopy showed that the oxidation of methanol was accompanied by the spillage of 0 to $50 \%$ of the input carbon as formaldehyde and dihydroxyacetone, the extent of which reflected the methanol dehydrogenase:hexulose phosphate synthase activity ratio and/or the energy status of the cells. It is concluded that the observed regulation of key enzymes of methanol and formaldehyde metabolism by the growth environment occurs in order to achieve the required in situ rates of energy conservation and carbon flux demanded by the imposed growth rate, and that the spillage of formaldehyde and dihydroxyacetone reflects limitations on metabolism imposed by kinetic and/or metabolite pool effects.

\section{INTRODUCTION}

Methylophilus methylotrophus is an aerobic methylotroph which oxidizes methanol to formaldehyde using a PQQ-linked methanol dehydrogenase. The reducing equivalents are subsequently transferred to molecular oxygen via a well-characterized, energy-conserving respiratory chain (see Anthony, 1982; Beardmore-Gray et al., 1983; Froud \& Anthony, 1984a, $b$; Patchett et al., 1985).

The formaldehyde is normally either converted into pyruvate via the assimilatory ribulose monophosphate cycle or oxidized to carbon dioxide via the dissimilatory cycle (Beardsmore et al., 1982). In both cases the first enzyme is hexulose phosphate synthase, which fixes the potentially toxic formaldehyde by condensing it with ribulose 5-phosphate to form hexulose 6phosphate. The latter is then converted via fructose 6-phosphate to glucose 6-phosphate, and thence to 6-phosphogluconate using an $\mathrm{NAD}(\mathrm{P})^{+}$-linked glucose-6-phosphate dehydrogenase. The 6-phosphogluconate stands at a metabolic crossroads, and is therefore either assimilated via Entner-Doudoroff cleavage or oxidatively decarboxylated to ribulose 5-phosphate under the action of separate $\mathrm{NAD}^{+}$-linked and $\mathrm{NAD}(\mathrm{P})^{+}$-linked 6-phosphogluconate dehydrogenases. Both of these enzymes are inhibited by high $[\mathrm{ATP}]:[\mathrm{AMP}]$ and/or $[\mathrm{NAD}(\mathrm{P}) \mathrm{H}]:\left[\mathrm{NAD}(\mathrm{P})^{+}\right]$ ratios.

Three other pathways exist for the oxidation of formaldehyde. All are linear routes in which formate, produced by the action of methanol dehydrogenase or of very low activity formaldehyde and aldehyde dehydrogenases, is subsequently oxidized to carbon dioxide by an

\footnotetext{
Abbreviations: CDTA, trans-1,2-diaminocyclohexane, $N, N, N^{\prime}, N^{\prime}$-tetraacetate; DCPIP, 2,6-dichlorophenolindophenol; FCCP, carbonyl cyanide $p$-trifluoromethoxyphenylhydrazone; PMS, phenazine methosulphate; $P Q Q$, pyrroloquinoline quinone.
} 
$\mathrm{NAD}^{+}$-linked formate dehydrogenase (see Anthony, 1982; Beardsmore et al., 1982; Page \& Anthony, 1986).

This paper describes the regulation by the growth environment of key enzymes of methanol and formaldehyde metabolism in $M$. methylotrophus, and the effect that these changes have on the spillage of formaldehyde and other metabolites during the oxidation of methanol.

\section{METHODS}

Growth of bacteria. M. methylotrophus (NCIB 10515) was grown in continuous culture $\left(900 \mathrm{ml}: 40^{\circ} \mathrm{C}\right.$ ) in the methanol-minimal salts medium described by Dawson \& Jones (1981). For methanol-limited growth the input methanol concentration was $44.5 \mathrm{~mm}$ and the air supply was adjusted to maintain the dissolved oxygen concentration at not less than $50 \%$ saturation. For oxygen-limited growth the input methanol concentration was doubled and the air supply was decreased such that the dissolved oxygen concentration was too low to be detected. Five dilution rates were used for each nutrient limitation $\left(D=\mu=0.04,0.18,0.31,0.45\right.$ and $0.53 \mathrm{~h}^{-1} ; \mu_{\max }$ $\left.0.55 \mathrm{~h}^{-1}\right)$.

Preparation of whole cell suspensions and subcellular fractions. After harvesting, cells were washed once in $20 \mathrm{mM}$ glycylglycine buffer, $\mathrm{pH} 7 \cdot 0$, and resuspended in the same buffer to a cell density of 20 to $40 \mathrm{mg} \mathrm{dry} \mathrm{wt} \mathrm{ml}^{-1}$. The glycylglycine buffer was replaced by $20 \mathrm{mM}$-sodium/potassium phosphate buffer, $\mathrm{pH} 7 \cdot 2$, plus $5 \mathrm{mM}$-magnesium chloride when the cells were subsequently used for the assay of hexulose phosphate synthase.

The washed cell suspension $\left(10 \mathrm{mg} \mathrm{dry} \mathrm{wt} \mathrm{ml}^{-1}\right)$ was sonicated at full power for $4 \times 30 \mathrm{~s}$ periods with appropriate cooling and then centrifuged at $15000 \mathrm{~g}$ for $15 \mathrm{~min}$ to produce a cell-free extract. The latter was subsequently centrifuged at $100000 \mathrm{~g}$ for $1 \mathrm{~h}$ to yield a clear supernatant and a red-brown membrane fraction.

Measurement of enzyme activities. Methanol and formate oxidase systems were assayed polarographically using a Clark-type oxygen electrode and a $4 \mathrm{ml}$ reaction volume (Carver \& Jones, 1984). The reaction mixture contained $20 \mathrm{mM}$-glycylglycine buffer, $\mathrm{pH} 7.0$, plus an appropriate amount of cells, and the reaction was started by the addition of either $10 \mathrm{~mm}$-methanol or $20 \mathrm{~mm}$-potassium formate. If required, FCCP was added $1 \mathrm{~min}$ before addition of substrate. The respiration rate was corrected for endogenous activity.

Methanol dehydrogenase activity was assayed spectrophotometrically in $20 \mathrm{~mm}-\mathrm{Tris} / \mathrm{HCl}$ buffer $\mathrm{pH} 8.5$, with PMS and DCPIP as electron acceptors. The reaction mixture $(1 \mathrm{ml})$ also contained an appropriate amount of cells plus $15 \mathrm{mM}$-ammonium chloride, $1 \mathrm{mM}$-potassium cyanide and $10 \mathrm{mM}$-methanol as described previously (Carver $e t$ al., 1984).

Hexulose phosphate synthase activity was assayed using a discontinuous method which involved measuring the rate of disappearance of formaldehyde in the presence of ribulose 5-phosphate generated in situ from ribose 5phosphate (Ferenci et al., 1974). The reaction mixture $(1 \mathrm{ml})$ contained $50 \mathrm{~mm}$-sodium/potassium phosphate buffer, pH 7.2, $2.5 \mathrm{~mm}$-magnesium chloride, $5 \mathrm{~mm}$-formaldehyde, $5 \mathrm{~mm}$-ribose 5-phosphate and 1.75 units of phosphoribosisomerase (Sigma) which were allowed to stand for $15 \mathrm{~min}$ before the addition of cell extract. Samples $(0.1 \mathrm{ml})$ were removed at 10 or $15 \mathrm{~s}$ intervals and rapidly mixed with $1 \mathrm{ml} 10 \%(w / v)$ trichloroacetic acid. The concentration of formaldehyde was determined colorimetrically using Nash reagent (Nash, 1953).

Glucose-6-phosphate dehydrogenase and two 6-phosphogluconate dehydrogenases were assayed spectrophotometrically by measuring the rate of reduction of $\mathrm{NAD}^{+}$or $\mathrm{NADP}^{+}$at $\mathrm{pH} 8.0$ as described by Beardsmore et al. (1982).

All enzyme assays were done at $40^{\circ} \mathrm{C}$.

Measurement of overflow metabolism. Washed cell suspensions ( $5 \mathrm{ml}$ of approximately 1 to $3 \mathrm{mg}^{2}$ cells ml ${ }^{-1}$ in $20 \mathrm{mM}$-glycylglycine buffer, $\mathrm{pH} 7.0$ ) were incubated for approximately $5 \mathrm{~min}$ at $40^{\circ} \mathrm{C}$ either in open beakers or in a Rank oxygen electrode before addition of $10 \mathrm{mM}$-methanol. After $1 \mathrm{~min}$ the reaction was terminated by the addition of ice-cold $25 \%(\mathrm{v} / \mathrm{v})$ perchloric acid $(1.6 \mathrm{ml})$ and the mixture was centrifuged to yield a clear supernatant which was decanted off and neutralized with $6 \mathrm{M}$-potassium hydroxide plus $1.2 \mathrm{M}$-Tris as described by McKay $e t$ al. (1982). The concentrations of formaldehyde and methanol in the neutralized mixture were determined colorimetrically (Nash, 1953) and gas-chromatographically respectively; the latter method used a Pye-Unicam gas chromatograph with a $2 \mathrm{~m}$ Tenax polystyrene resin column $(60-80 \mathrm{mesh})$ operating at $150^{\circ} \mathrm{C}$.

Analysis of methanol oxidation using ${ }^{13} \mathrm{C} \mathrm{NMR}$ spectroscopy. ${ }^{13} \mathrm{C}$ NMR spectra were recorded at $75 \cdot 4 \mathrm{MHz}$ using a Bruker AM300 spectrometer. Washed cell suspensions (typically $4.5 \mathrm{ml}$ of $20 \mathrm{mg}^{\text {cells ml }} \mathrm{m}^{-1}$ containing $10 \%$ $\mathrm{D}_{2} \mathrm{O}$ ) were placed in NMR tubes of external diameter $10 \mathrm{~mm}$ and bubbled with oxygen-free nitrogen at a rate of approximately $15 \mathrm{ml} \mathrm{min}^{-1}$ using a simple flow-apparatus (Santos \& Turner, 1986). [ $\left.{ }^{13} \mathrm{C}\right]$ Methanol (92 atom\%; $30 \mathrm{mM}$ ) was then added and the gas phase was changed to pure oxygen.

The spectra were obtained using $20^{\circ}$ pulses, with 8192 points acquired in $0.25 \mathrm{~s}$ between pulses to define a spectral width of 220 p.p.m. Protons were continuously decoupled by means of $180^{\circ}$ pulses (Milner \& Turner, 1965 ) using an average power of approximately $1 \mathrm{~W}$. The temperature of the sample under these conditions was $27 \pm 2{ }^{\circ} \mathrm{C}$. Zero filling to $16 \mathrm{~K}$ points, and exponential multiplication corresponding to a line broadening of $10 \mathrm{~Hz}$, 
was used prior to Fourier transformation. In this manner, the variation in the principal signals could be followed with a time resolution of $15 \mathrm{~s}$. Signal intensities were converted to concentrations using the ratios obtained under typical and quantitative conditions from an anaerobic cell suspension.

\section{RESULTS}

\section{Effect of growth conditions and FCCP on respiratory activities}

Whole cells of $M$. methylotrophus prepared from methanol-limited continuous cultures $(D=$ $0.18 \mathrm{~h}^{-1}$ ) exhibited high rates of respiration in the presence of either methanol or ethanol

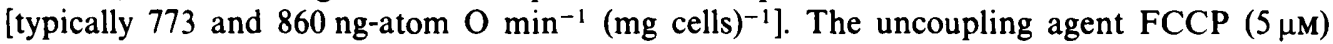
stimulated the activity of the methanol oxidase system by $10 \pm 2 \%$ but had no effect on the rate of ethanol oxidation. As both methanol and ethanol are oxidized to their corresponding aldehydes by the respiratory chain-linked methanol dehydrogenase, but only the formaldehyde is further metabolized by the ribulose monophosphate cycles, these results suggest that the observed stimulation of methanol oxidation by FCCP reflects an increased rate of intermediary metabolism rather than a loss of respiratory control.

The rate of methanol oxidation by cells prepared from methanol-limited cultures of $M$. methylotrophus was high and essentially constant over the entire range of dilution rates investigated $\left(0.04\right.$ to $\left.0.53 \mathrm{~h}^{-1} ; \mu_{\max }=0.55 \mathrm{~h}^{-1}\right)$, whereas the activity of cells prepared from oxygen-limited cultures was very low at a dilution rate of $0.04 \mathrm{~h}^{-1}$ and increased substantially as the dilution rate was increased (Fig. 1; see also Greenwood \& Jones, 1986). Similar patterns were observed when the methanol oxidase system was assayed by measuring the consumption of methanol instead of oxygen. In neither type of cells did the methanol oxidation rate change in parallel with the concentration or activity of methanol dehydrogenase, thus indicating that the further oxidation of formaldehyde is particularly pronounced in cells prepared from higher dilution rate cultures. FCCP $(5 \mu \mathrm{M})$ stimulated the rate of oxygen consumption by a similar amount in all types of cells, i.e. by an average of $90 \mathrm{ng}$-atom $\mathrm{O} \mathrm{min}^{-1}(\mathrm{mg} \text { cells) })^{-1}$ in cells from methanol-limited cultures, and by average of $122 \mathrm{ng}$-atom $\mathrm{O} \mathrm{\textrm {min } ^ { - 1 }}(\mathrm{mg} \text { cells) })^{-1}$ in cells prepared from oxygen-limited cultures. In the former case this was equivalent to 10 to $14 \%$ at all dilution rates, whereas in the latter case it was equivalent to a decrease from 81 to $18 \%$ as the dilution rate was increased (and thus reflected the increasing respiration rate in the absence of FCCP). Similar patterns of stimulation by FCCP were also observed when the activity of the methanol oxidase was assayed by measuring the rate of methanol disappearance.

The rate of formate oxidation by whole cells of $M$. methylotrophus followed a similar pattern to methanol dehydrogenase activity, i.e. for cells prepared from methanol-limited cultures the oxidation rate decreased by almost two-thirds as the dilution rate was increased from 0.04 to $0.53 \mathrm{~h}^{-1}$, whereas for cells prepared from oxygen-limited cultures the oxidation rate remained low and essentially constant over the entire range of dilution rates. The rate of formate oxidation was either unaffected or slightly inhibited by FCCP $(5 \mu \mathrm{M})$.

\section{Effect of growth conditions on the activities of selected enzymes of the ribulose monophosphate cycle}

Analyses of selected ribulose monophosphate cycle enzymes in cell-free extracts of $M$. methylotrophus revealed quite different activity patterns as a function of dilution rate to those exhibited by methanol dehydrogenase and the formate oxidase system (Fig. 2). Hexulose phosphate synthase activity remained high and essentially constant at all dilution rates in cells from either methanol-limited or oxygen-limited cultures. The ratio of methanol dehydrogenase activity to hexulose phosphate synthase activity therefore decreased with increasing dilution rate in methanol-limited cells, but remained low at all dilution rates in oxygen-limited cells. In contrast to hexulose phosphate synthase, the activities of the glucose-6-phosphate dehydrogenase (assayed with $\mathrm{NAD}^{+}$or NADP ${ }^{+}$) and of the NAD ${ }^{+}$-linked and NADP+-linked 6phosphogluconate dehydrogenases in both types of cells all increased by 2 to 3 -fold as the dilution rate was increased from 0.04 to $0.53 \mathrm{~h}^{-1}$. 


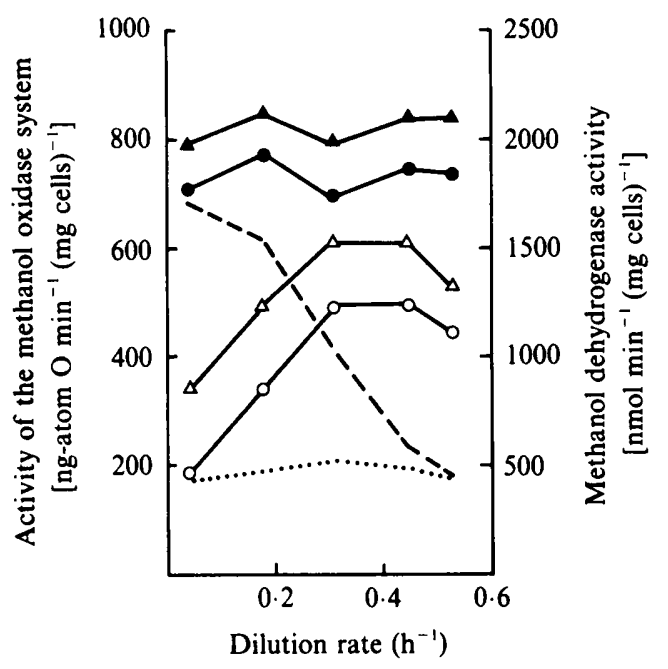

Fig. 1. Effect of nutrient limitation, dilution rate and FCCP on the activity of the methanol oxidase system of $\boldsymbol{M}$. methylotrophus. Respiratory activities of washed cell suspensions were assayed in the presence $(\Lambda, \triangle)$ or absence $(O, O)$ of FCCP $(5 \mu \mathrm{M})$ as described in Methods. Methanol dehydrogenase activity $(---, \cdots \cdots)$ is taken from Greenwood \& Jones (1986). Cells were from either methanol-limited $(O, \Delta,--)$ or oxygen-limited $(O, \Delta, \cdots)$ cultures. The values quoted are the mean of between three and nine independent determinations.
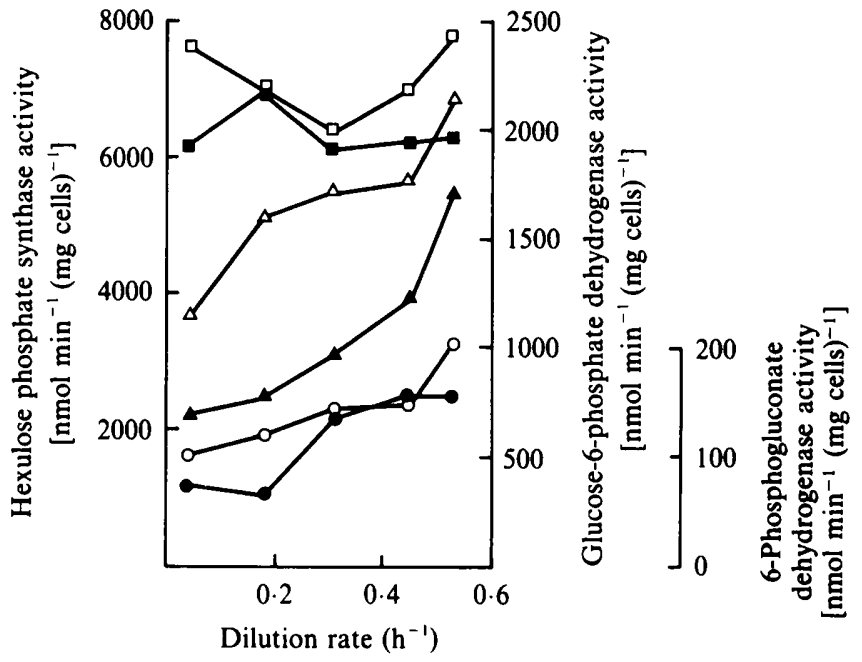

Fig. 2. Effect of nutrient limitation and dilution rate on the activities of selected ribulose monophosphate cycle enzymes of $\boldsymbol{M}$. methylotrophus. Cell-free extracts were assayed as described in Methods for the following activities: hexulose phosphate synthase $(\square, \square)$, glucose-6-phosphate dehydrogenase (NADP+-linked; $\Delta, \triangle$ ) and 6-phosphogluconate dehydrogenase (NADP+-linked; $\boldsymbol{O}$, O). Cells were from either methanol-limited $(\square, \Delta, 0)$ or oxygen-limited $(\square, \triangle, 0)$ cultures. The values quoted are the mean of between two and eight independent determinations.

\section{Effect of growth conditions and FCCP on the spillage of formaldehyde}

The observation that the growth of $M$. methylotrophus under different nutrient limitations and/or at different dilution rates yields cells which exhibit wide variations in the activity ratios of the first two enzymes of methanol metabolism (methanol dehydrogenase and hexulose 


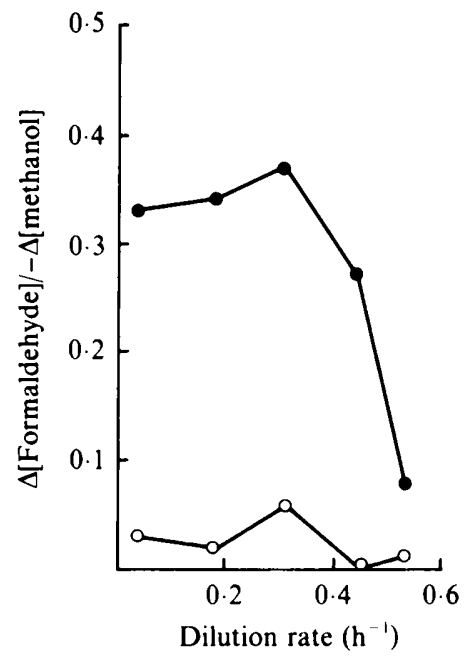

Fig. 3

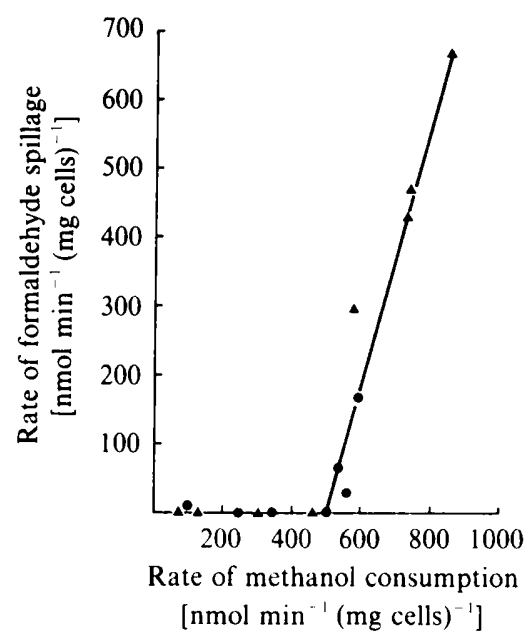

Fig. 4

Fig. 3. Effect of nutrient limitation and dilution rate on the overflow of formaldehyde during methanol oxidation by $M$. methylotrophus. Washed cell suspensions were allowed to oxidize methanol for $1 \mathrm{~min}$ at $40^{\circ} \mathrm{C}$ in open beakers or in the reaction chamber of a Rank oxygen electrode; the reaction was then stopped and the amounts of methanol oxidized, oxygen consumed and formaldehyde spilled were assayed as described in Methods. Cells were from either methanol-limited (O) or oxygen-limited $(O)$ cultures.

Fig. 4. Effect of varying the rate of methanol oxidation on the overflow of formaldehyde by $M$. methylotrophus grown under methanol-limited conditions $\left(D=0 \cdot 18 \mathrm{~h}^{-1}\right)$. Washed cell suspensions were allowed to oxidize methanol for $1 \mathrm{~min}$ at $40^{\circ} \mathrm{C}$; the reaction was then stopped and the amounts of methanol oxidized, oxygen consumed and formaldehyde spilled were assayed as described in Methods. The rate of methanol oxidation was varied by carrying out the reaction either in the presence of $10 \mathrm{mM}$ methanol plus different concentrations of $\operatorname{CDTA}(0,10,20$ or $30 \mu \mathrm{M})(\boldsymbol{\Lambda})$ or at sub-saturating concentrations of methanol produced by bleeding $10 \mathrm{~mm}$-methanol into the reaction mixture at different rates using a low capacity peristaltic pump (O). Both sets of results are each a composite of two separate experiments.

phosphate synthase) suggests that exposure of cells to saturating concentrations of methanol in vitro may lead to a variable overproduction of formaldehyde. Analyses of methanol and formaldehyde concentrations in reaction mixtures after whole cells had been allowed to oxidize methanol for 1 min largely confirmed this prediction (Fig. 3). Approximately $34 \%$ of the methanol consumed by cells prepared from methanol-limited cultures grown at a dilution rate of $0.04 \mathrm{~h}^{-1}$ was spilled as formaldehyde compared with only approximately $8 \%$ following growth at a dilution rate of $0.53 \mathrm{~h}^{-1}$; the extent of formaldehyde overflow at each dilution rate was slightly stimulated by FCCP. In contrast, cells prepared from cultures grown under oxygen-limitation spilled only approximately $2 \%$ of their consumed methanol as formaldehyde, irrespective of the dilution rate, but this spillage was substantially increased in the presence of FCCP and an overflow pattern was observed which resembled that shown by cells grown under methanollimitation. Similar results were also obtained when formaldehyde overflow was measured as a function of oxygen uptake rather than methanol consumption.

Since the overflow of formaldehyde can be altered by varying either the concentration of methanol dehydrogenase (by changing the growth conditions) or the relative activities of the assimilatory and dissimilatory ribulose monophosphate cycles (using FCCP), it should also be possible to alter it by manipulating the activity of methanol dehydrogenase, e.g. by using either a chelating agent such as CDTA (Carver et al., 1984) or sub-saturating concentrations of methanol. When the methanol dehydrogenase activity of cells prepared from a methanol-limited 
culture $\left(D=0 \cdot 18 \mathrm{~h}^{-1}\right)$ was manipulated in this manner, significant spillage of formaldehyde occurred only when the rate of methanol oxidation exceeded approximately $500 \mathrm{nmol} \mathrm{min}-1$ (mg cells) ${ }^{-1}$ (Fig. 4), a rate which presumably reflects the activity of the hexulose phosphate synthase under these conditions. A similar pattern was also obtained when the overflow of formaldehyde was measured as a function of the respiration rate, significant spillage occurring only when the rate exceeded approximately $420 \mathrm{ng}$-atom $\mathrm{O} \mathrm{min}^{-1}\left(\mathrm{mg}\right.$ cells) ${ }^{-1}$.

\section{Effect of nutrient-limitation and FCCP on the oxidation of $\left[{ }^{13} \mathrm{C}\right]$ methanol}

Metabolism of $\left[{ }^{13} \mathrm{C}\right]$ methanol by cells of $M$. methylotrophus from methanol-limited cultures $\left(D=0.18 \mathrm{~h}^{-1}\right)$ was observed only under aerobic conditions, as evidenced by the nondisappearance of the singlet at $50 \cdot 1 \delta$ in the proton-decoupled ${ }^{13} \mathrm{C}$ NMR spectrum when the cells were bubbled with oxygen-free nitrogen, and by its progressive disappearance when the gas phase was changed to pure oxygen. The disappearance of this signal was accompanied by the appearance of several new signals, the largest of which were identified from their chemical shifts as formaldehyde hydrate $(83.2 \delta)$, formate $(171.7 \delta)$, dihydroxyacetone $(213.1 \delta$ and $66.0 \delta)$ and dihydroxyacetone hydrate $(96.5 \delta$ and $64.9 \delta)$. Weak signals indicative of carbon dioxide, bicarbonate and pyruvate, together with several signals due to the glycylglycine buffer in which the cells were suspended, were also observed. The signals arising from dihydroxyacetone, dihydroxyacetone hydrate and pyruvate all showed evidence of ${ }^{13} \mathrm{C}-{ }^{13} \mathrm{C}$ coupling.

The acquisition of ${ }^{13} \mathrm{C}$ NMR spectral transients over successive 1 min periods allowed a timecourse of these changes to be constructed (Fig. 5a). Methanol was consumed at a constant rate of approximately $100 \mathrm{nmol} \mathrm{min}^{-1}(\mathrm{mg} \text { cells) })^{-1}$. After correcting for the difference in temperature (i.e. $27^{\circ} \mathrm{C}$ cf. $40{ }^{\circ} \mathrm{C}$; see Figs 3 and 4) between these experiments and the earlier ones (in which the disappearance of methanol had been assayed discontinuously by gas chromatography), this value was significantly lower than expected. As the appropriate control experiments showed that the respiration of the cells in the NMR spectrometer tube was not limited by oxygen, it must be concluded that a significant decrease in the activity of the methanol dehydrogenase had occurred during the preparation of the cells for NMR spectroscopy. This was supported by the observation that formaldehyde spillage occurred much later and in more variable, but generally lower, concentrations than in the previous experiments.

The formaldehyde disappeared at a relatively slow rate when the methanol was exhausted, and was transiently replaced by a low concentration of formate, thus confirming that in the absence of excess methanol the formaldehyde can be oxidized by a linear route; similar observations have been reported for the oxidation of methanol by whole cells of the methanotroph Methylosinus trichosporium OB3b (Cornish et al., 1984). Most importantly, the oxidation of methanol was accompanied by the linear production of dihydroxyacetone at a buildup rate that was between 25 and $50 \%$ of the rate of $\left[{ }^{13} \mathrm{C}\right]$ methanol utilization. The dihydroxyacetone accumulated to a maximum concentration equivalent to 20 to $50 \%$ of the input methanol immediately before exhaustion of formaldehyde, after which its concentration decreased at a rate which was approximately 50 times slower than the rate of methanol oxidation. The line widths of the various signals were in all cases characteristic of unbound, extracellular metabolites.

When these experiments were repeated in the presence of FCCP (Fig. $5 b$ ), the rate of methanol oxidation increased to an average of $140 \mathrm{nmol} \mathrm{min}^{-1}(\mathrm{mg} \text { cells) })^{-1}$ and formaldehyde accumulated at a much faster rate and to much higher levels. As a result, formate appeared before the methanol was exhausted, possibly because the formaldehyde was able to compete more effectively against methanol for the methanol dehydrogenase (but see Page \& Anthony, 1986). The rate of accumulation of dihydroxyacetone was very substantially diminished under these essentially de-energized conditions.

Cells prepared from oxygen-limited cultures grown at a dilution rate of $0.18 \mathrm{~h}^{-1}$ oxidized methanol at an average rate of $70 \mathrm{nmol} \mathrm{min}{ }^{-1}(\mathrm{mg} \text { cells) })^{-1}$ (Fig. $5 c$ ), which was again lower than expected. No evidence was obtained for the spillage of formaldehyde or other metabolites. In the presence of FCCP (Fig. 5d) the rate of methanol oxidation increased to an average of $90 \mathrm{nmol} \mathrm{min}{ }^{-1}$ (mg cells) ${ }^{-1}$ and significant amounts both of formaldehyde and formate were 
(a)

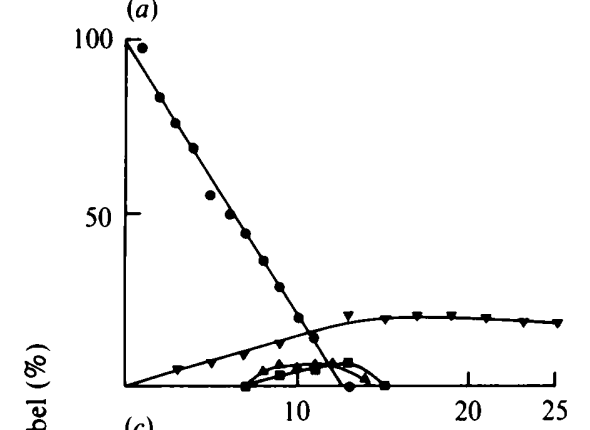

0

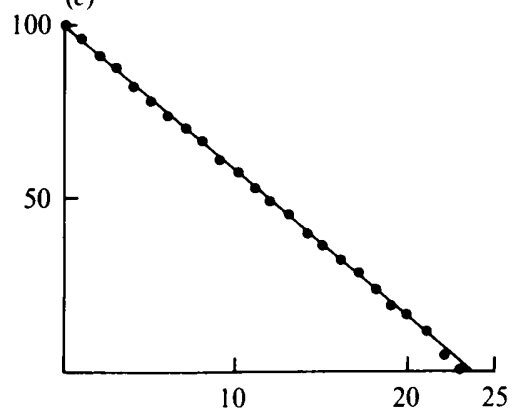

(b)
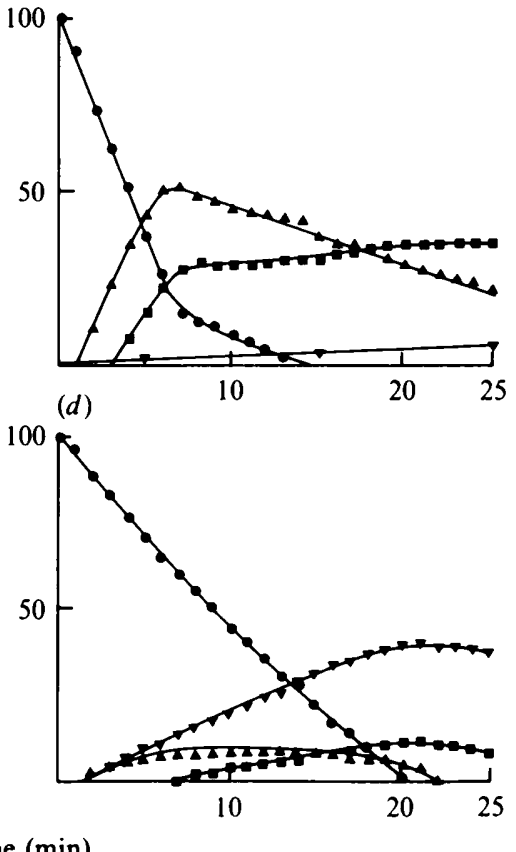

Fig. 5. Effect of FCCP on the metabolism of $\left[{ }^{13} \mathrm{C}\right]$ methanol by whole cells of $M$. methylotrophus prepared from methanol-limited $(a, b)$ or oxygen-limited $(c, d)$ cultures $\left(D=0 \cdot 18 \mathrm{~h}^{-1}\right)$. The cells were allowed to oxidize $30 \mathrm{~mm}-\left[{ }^{13} \mathrm{C}\right] \mathrm{methanol}$ at $27 \pm 2{ }^{\circ} \mathrm{C}$ as described in Methods. The concentrations of methanol $(\boldsymbol{\theta})$, formaldehyde $(\boldsymbol{\Delta})$, formate $(\boldsymbol{\nabla})$ and dihydroxyacetone $(\boldsymbol{\nabla})$ were calculated from the signal intensities which were observed in sequential ${ }^{13} \mathrm{C}$ NMR spectra recorded at $1 \mathrm{~min}$ intervals following the addition of the methanol. (a), (c), No FCCP; $(b),(d)$, plus $5 \mu \mathrm{M}-\mathrm{FCCP}$.

observed, together with a rapid and substantial accumulation of dihydroxyacetone amounting to between 20 and $50 \%$ of the input label.

\section{DISCUSSION}

It is now well established that washed cells of $M$. methylotrophus do not exhibit respiratory control, and that low concentrations of the uncoupling agent FCCP rapidly dissipate the protonmotive force to generate a low intracellular [ATP]:[AMP] ratio (Dawson \& Jones, 1982; Patchett et al., 1985). The ability of FCCP to stimulate oxygen uptake with methanol, but not ethanol, as substrate is therefore commensurate with the hypothesis that this stimulation is the net result of the low [ATP]:[AMP] ratio increasing the rate of formaldehyde dissimilation and decreasing the rate of formaldehyde assimilation (by virtue of its ability to stimulate 6phosphogluconate dehydrogenase activity), rather than the release of classical respiratory control by the low protonmotive force. However, as the rate of methanol consumption also increases, and the resultant formaldehyde is readily spilled, there must be some sort of direct control over methanol dehydrogenase activity which is specific to methanol and is released following the addition of FCCP. The nature of this control process is currently uncertain and clearly merits further investigation. It is unlikely that it involves the recently discovered modifier-protein since the latter appears to exert identical effects on the oxidation of both methanol and ethanol (Ford et al., 1985; Page \& Anthony, 1986).

It has previously been shown that the regulation by the growth environment of methanol dehydrogenase and cytochrome oxidase activity in $M$. methylotrophus enables the respiratory chain methanol oxidase system to be precisely tuned to the standing concentration of methanol 
or oxygen in the growth medium such as to maintain an in situ rate of respiration and of associated energy conservation that satisfies the demands of the imposed growth rate (Greenwood \& Jones, 1986). The results described above show that some of the key enzymes involved in the subsequent metabolism of formaldehyde are regulated quite differently from methanol dehydrogenase. Whereas methanol dehydrogenase and the formate oxidase system are repressed by the presence of high concentrations of methanol in the growth medium, hexulose phosphate synthase is constitutive and the glucose-6-phosphate and 6-phosphogluconate dehydrogenases are regulated only by the dilution rate. The latter presumably occurs in order to achieve the required in situ rate of carbon flux demanded by the growth rate, the hexulose phosphate synthase activity being sufficient to support growth at all dilution rates up to $\mu_{\max }$.

The spillage of potentially toxic formaldehyde during the oxidation of methanol by $M$. methylotrophus in vitro reflects the relative activities of the methanol dehydrogenase and the hexulose phosphate synthase, and thus explains the behaviour of methanol-limited cultures of this organism following a pulsed addition of methanol or a sudden increase in dilution rate of greater than approximately $0 \cdot 15 \mathrm{~h}^{-1}(\mathrm{R}$. B. Vasey, S. J. Bungard \& P. J. Senior, personal communication; C. W. Jones \& J. A. Greenwood, unpublished). At low dilution rates the standing concentration of methanol in the growth medium is extremely low, and the methanol dehydrogenase concentration is therefore high in order to achieve the required rate of methanol consumption. If a pulse of methanol is added to the growth medium, or if the dilution rate is suddenly increased, the standing concentration of methanol rises and elicits a large increase in the rate of methanol oxidation which exceeds the capacity of the hexulose phosphate synthase to remove the resultant formaldehyde. When the cells again become methanol-limited, the spilled formaldehyde is largely re-oxidized by the linear route involving formate. Imperfect mixing of the methanol in the growth medium, as may occur under large-scale conditions, will also lead to significant oxidation of formaldehyde via this route which is energetically less favourable than the dissimilatory ribulose monophosphate cycle. The use of an appropriate inhibitor of methanol dehydrogenase, or of a mutant which produces restricted amounts of the enzyme, should therefore lead to an increase in the growth yield of this organism.

No such changes occur in oxygen-limited cultures following a pulse of methanol or oxygen, or after a sudden increase in dilution rate, since they cannot increase their rate of methanol oxidation under these conditions. The failure of these cells to spill formaldehyde, except under totally de-energized non-physiological conditions, is reflected in their low rate of formate oxidation.

These events were also seen in vitro during the oxidation of $\left[{ }^{13} \mathrm{C}\right] \mathrm{methanol}$ by $M$. methylotrophus, when the spillage of formaldehyde and formate was accompanied by the production of variable amounts of dihydroxyacetone. As this organism does not contain dihydroxyacetone synthase (Anthony, 1982), this product presumably arises from pyruvate produced via the assimilatory ribulose monophosphate cycle together with three molecules of $\mathrm{PQQH}_{2}$ (reduced methanol dehydrogenase) and one of $\mathrm{NAD}(\mathrm{P}) \mathrm{H}$. The subsequent conversion of pyruvate to dihydroxyacetone phosphate uses three ATP and one NADH, but as it releases only two molecules of inorganic phosphate the dihydroxyacetone phosphate must be hydrolysed to dihydroxyacetone in order to maintain the intracellular phosphate pool. Since considerably more than three molecules of $\mathrm{PQQH}_{2}$ are oxidized for each molecule of dihydroxyacetone produced, it follows that the methanol oxidase system exhibits an ATP/O quotient of significantly less than 1 (see also Patchett et al., 1985).

The observation that whole cells re-oxidize spilled formaldehyde at a rate which is significantly slower than the original rate of methanol oxidation is compatible with the recent claim that a modifier protein alters the kinetic parameters of methanol dehydrogenase such as to diminish its ability to oxidize formaldehyde (Page et al., 1986). It is likely that this enzyme is still used, however, since the activity of the non-specific aldehyde dehydrogenase is far too slow to account for the observed rate of formaldehyde oxidation.

The ability of FCCP to stimulate formaldehyde spillage from cells prepared from both methanol-limited and oxygen-limited cultures, but to cause opposite effects on the rate of accumulation of dihydroxyacetone, may reflect the complicated changes that de-energization 
brings about in the kinetics of several interlinked metabolic pathways. Since we do not know the pool sizes of the major metabolites, and have only a limited knowledge of the kinetic constants of the relevant enzymes, it is currently impossible to describe these changes in more detail.

The authors are indebted to the SERC and ICI for the award of a CASE Studentship (to S. M. B.), to Dr M. A. Carver for carrying out the methanol assays, and to Drs P. J. Senior, S. J. Bungard and M. A. Carver for useful discussions.

\section{REFERENCES}

ANTHONY, C. (1982). The Biochemistry of Methylotrophs. London: Academic Press.

Beardmore-Gray, M., O’KeEFe, D. \& ANTHony, C. (1983). The methanol:cytochrome $c$ oxidoreductase activity of methylotrophs. Journal of General Microbiology 129, 923-933.

Beardsmore, A. J., Aperghis, P. N. G. \& Quayle, J. R. (1982). Characterization of the assimilatory and dissimilatory pathways of carbon metabolism during growth of Methylophilus methylotrophus on methanol. Journal of General Microbiology 128, 14231439.

Carver, M. A., Humphrey, K. M., Patchett, R. A. \& JONES, C. W. (1984). The effect of EDTA and related chelating agents on the oxidation of methanol by the methylotrophic bacterium Methylophilus methylotrophus. European Journal of Biochemistry 138, 611615.

Carver, M. A. \& Jones, C. W. (1984). The role of $c$-type cytochromes in the terminal respiratory chain of the methylotrophic bacterium Methylophilus methylotrophus. Archives of Microbiology 139, 76-82.

CoRnish, A., Nicholls, K. M., Scott, D., Hunter, B. K., Aston, W. J., Higgins, I. J. \& SANDERS, J. K. M. (1984). In vivo ${ }^{13} \mathrm{C}$ NMR investigations of methanol oxidation by the obligate methanotroph Methylosinus trichosporium OB3b. Journal of General Microbiology 130, 2565-2575.

DAwson, M. J. \& JoNES, C. W. (1981). Respirationlinked proton translocation in the obligate methylotroph Methylophilus methylotrophus. Biochemical Journal 194, 915-924.

DAwson, M. J. \& Jones, C. W. (1982). The protonmotive force and phosphorylation potential developed by whole cells of the methylotrophic bacterium Methylophilus methylotrophus. Archives of Microbiology 133, 55-61.

Ferenci, T., Strom, T. \& Quayle, J. R. (1974). Purification and properties of 3-hexulose phosphate synthase and phospho-3-hexuloisomerase from Methylococcus capsulatus. Biochemical Journal 144, $477-486$.
Ford, S. J., Page, M. D. \& Anthony, C. (1985). The role of a methanol dehydrogenase modifier protein and aldehyde dehydrogenase in the growth of Pseudomonas AM1 on 1,2-propanediol. Journal of General Microbiology 131, 2173-2182.

Froud, S. J. \& ANTHONY, C. (1984a). The purification and characterization of the $o$-type cytochrome oxidase from Methylophilus methylotrophus and its reconstitution into a 'methanol oxidase' electron transport chain. Journal of General Microbiology 130, 2201-2212.

Froud, S. J. \& ANTHony, C. (1984b). The roles of cytochrome $c$ in the membranes of Methylophilus methylotrophus. Journal of General Microbiology 130, 3319-3325.

Greenwood, J. A. \& Jones, C. W. (1986). Environmental regulation of the methanol oxidase system of Methylophilus methylotrophus. Journal of General Microbiology 132, 1247-1256.

MCKay, A., Quilter, J. A. \& Jones, C. W. (1982). Energy conservation in the extreme thermophile Thermus thermophilus HB8. Archives of Microbiology 131, 43-50.

Milner, R. S. \& Turner, D. W. (1965). Spin decoupling using pulsed radiofrequency magnetic fields. Journal of the Chemical Society 31-32.

NaSH, T. (1953). The colourimetric estimation of formaldehyde by means of the Hanzsch reaction. Biochemical Journal 55, 416-421.

PAGE, M. D. \& ANTHONY, C. (1986). Regulation of formaldehyde oxidation by the methanol dehydrogenase modifier proteins of Methylophilus methylotrophus and Pseudomonas AM1. Journal of General Microbiology 132, 1553-1563.

Patchett, R. A., Quilter, J. A. \& Jones, C. W. (1985). Energy conservation in whole cells of the methylotrophic bacterium Methylophilus methylotrophus. Archives of Microbiology 141, 95-102.

SANTOS, H. \& TURNER, D. L. (1986). Characterisation of the improved sensitivity obtained using a flow method for oxygenating and mixing cell suspensions in NMR. Journal of Magnetic Resonance 68, 345-349. 